\title{
RES development trends that determine the sustainable development of the energy system of the future
}

\author{
Tatiana Meshcheryakova ${ }^{1, *}$ and Andrey Pigurin ${ }^{l}$ \\ ${ }^{1}$ Moscow State University of Civil Engineering, 129337, 26 Yaroslavskoye Shosse, Moscow, Russia
}

\begin{abstract}
To ensure reliable energy supply, it is necessary to solve a number of basic tasks: flexibility of energy systems, uninterrupted supply of energy, its availability to end consumers, resource efficiency and environmental safety. Sustainable development of the energy system involves changes along the entire energy conversion chain - from fuel and renewable generation and transmission of energy to optimizing its consumption. Many countries prioritize the development of renewable energy as the basis for low-carbon economic growth. Renewable energy sources contribute to the development of popular technologies not only in the field of sun and wind, but also in energy storage, hydrogen cycle, electric transport and e-mobility, energy efficiency of buildings, in the field of "smart" technologies, which ultimately affects improving the quality of life of people.
\end{abstract}

\section{Introduction}

Demand for energy is growing worldwide. The relevance of the research topic is due to both global trends and the specifics of countries characterized by the isolation of territories in individual regions.

Eleven million people today are employed in the renewable energy industry worldwide and an increasing number of countries are discovering the benefits of renewable energy (RES). RES are becoming competitive. National support programs, coupled with cost reduction due to technological progress and the need to respond to the challenges of climate change, have stimulated a sharp increase in renewable energy and the development of employment in the industry. Having reached serious proportions, the development of renewable energy sources all over the world is also facing serious economic challenges for state budgets and consumers, restrictions on the area under renewable energy sources, issues of utilization of equipment, environmental consequences, as well as political challenges.

are many questions related to the development of the global renewable energy industry: How to maintain and increase the pace of renewable energy development? What technological breakthroughs are planned in renewable energy? What are the prospects facing the Russian renewable energy industry, and what measures are proposed to increase

* Corresponding author: meshcheryakovats@mgsu.ru 
the share of renewable energy sources in the balance and export of technologies? When will the introduction of renewable energy have an impact on the quality of life of the population?

Since Soviet times, nuclear power and hydropower have been actively represented in Russia. But given the new market conditions and the geographical dispersion of territories, there is an emphasis in small energy.

The object of study is the global RES market.

The subject of the study is the process of transformation of the global energy system, taking into account the possibilities of using the renewable energy market.

The purpose of the study is to identify global trends in the development of renewable energy.

To achieve this goal in the research process, the following tasks were solved:

- characterize the global renewable energy market;

- evaluate the renewable energy market in Russia;

- to analyze the problems of the development of renewable energy.

\section{Materials and methods}

To identify global trends, data from Russian and European statistics are used. One of the most important information sources in the field of energy is also a collection of BP Energy Outlook 2019 edition, annually published by the largest energy company British Petroleum (BP). This collection contains the most extensive research and long-term forecasts in the energy sectors.

The most relevant and significant issues in the field of renewable energy were discussed at the international forum Russian Energy Week: 2019, which examined global challenges and trends in the development of renewable energy. The study took into account data from the International Renewable Energy Agency, whose management spoke at the event.

To analyze the regulatory framework and program documents in the field of renewable energy development, data from the Ministry of Energy of the Russian Federation were used.

When analyzing the renewable energy support mechanisms in the wholesale electricity and capacity market, the traditional graphical method was used, which allows comparing over the years the data on the costs of building the installed capacity of energy generating facilities, as well as the planned volumes of commissioning of these capacities in accordance with the type of generation. To identify global trends, data from Russian and European statistics are used. One of the most important information sources in the field of energy is also a collection of BP Energy Outlook 2019 edition, annually produced by the largest energy company British Petroleum (BP) [1].

\section{Results}

RES is developing at a faster pace. Analysis of the global renewable energy market over the past year demonstrates a significant reduction in energy prices obtained by generating energy from renewable energy sources. The market volume has almost doubled. Now $1 \mathrm{~kW}$ of energy produced using solar energy costs less than 2 cents, and from wind generation 1.5 cents per $1 \mathrm{~kW}$. Wind generation

became cheaper fell $2.5 \%$ compared with the previous year. Data for the 3 rd quarter of 2019 show that energy produced from fossil sources in the world market is much more expensive than energy generated from renewable energy sources. 
A global energy development strategy demonstrates the need for a gradual reduction in traditional energy sources. Representatives of energy agencies say that funding for the construction of coal stations is ending: more than 70 countries plan to achieve zero carbon emissions by 2050 [1].

Both technological and political transitions are being made from traditional energy models to new ones, with appropriate approaches and guarantees. The trend covers many countries, each with its own path. Nuclear energy, natural gas, renewable energy - all methods of generation should be considered and taken into account in the transition process, through regular monitoring. The cost of equipment used in renewable energy is gradually decreasing, and efficiency is increasing. Although renewable energy has shown significant structural progress, there are challenges to be answered in countries that are developing in an environmentally friendly and energy-efficient way. Such challenges include: technological problems and risks, insufficient development of the market and its regulation, lack of infrastructure. It is important to consider that renewable energy sources are unstable sources of energy and for their stabilization, a flexible interconnection of energy resources is necessary, as well as providing opportunities for energy storage. Also, in the new conditions of transition to renewable energy sources, it is necessary to consider the existing problems of cross-subsidization, which is growing every year.

However, with all the existing barriers, there is an important incentive for the development of renewable energy sources - environmental stabilization and reducing the dependence of economies on energy import conditions, respectively, creating conditions for the energy security of each country's energy supply [2-5].

It can be stated that the transition from traditional sources of energy to renewable energy is not fast enough. According to the forecasts of the International Renewable Energy Agency (IRENA), less than 12 years are left to go through the most important steps to transfer the global energy industry to new standards. Significantly reduce emissions of carbon and carbon into the atmosphere is necessary for 8.5 years.

Given the importance of renewable energy in the competitive energy generation market, the Russian Federation became a member of IRENA from July 22, 2015. Joining IRENA provided Russia with wide access to the existing practice of using and introducing renewable energy sources, the results of recent research, makes it possible to participate in the development of international standards and, in general, influence the development of renewable energy in the world. For the period from 2013 to 2020, Russia plans to introduce about $6 \mathrm{GW}$ of new generation capacities based on renewable energy sources.

According to expert data, the use of renewable energy in Russia has already increased to $11.3 \%$. It is planned that by 2030 RES will represent $30 \%$ of the energy market. This scenario will lead to a large export of energy ( $\$ 10$ billion - energy exports from renewable energy sources, \$ 24 billion - biofuels).

The world green energy began to develop taking into account the Kyoto Protocol. In 2015, the Paris Agreement, which was ratified in 2019, replaced the rules of the Kyoto Protocol. Now Russia is a full member of the international agreement. One of the important results was the development of the Renewable Energy Support Program on the basis of capacity supply agreements DPM-RES-1. According to the program, the horizons for the implementation of measures are determined, and guaranteed return on investors is provided. This program will be completed in 2024. The state, potential investors and the construction sector acted as reliable partners of the program. The continuation of the program will be DPM-RES-2, covering the horizons of 2025-2035. Financial support for the program will be about 400 billion rubles. The yield level is determined at $12 \%$, taking into account a possible adjustment to the yield on government bonds. The proportion of planned indicators for the structure of renewable energy sources, taking into account the opinions of members of the Russian Association of renewable energy sources: 37.5\% - solar energy, 62.5 - wind 
energy. As part of the program, the last commissioning of the renewable energy facility is planned for 2035. Renewable energy sources will achieve parity with traditional generation in 2036, and the program itself, taking into account payments, will be valid until 2050 .

Currently, a regulatory framework is being developed that will ensure the implementation of a renewable energy development program and determine the timing of the selection of capacities. There is a current Resolution "On stimulating the use of renewable energy sources in the retail electricity markets" dated January 23, 2015 No. 47, which is aimed at improving the support mechanism for generating facilities operating on the basis of the use of renewable energy sources in the retail markets, as well as stimulating the production of electric energy by such generating objects [6-10].

Consider the support mechanisms for generating facilities operating on the basis of MIE, defined as the main ones by the RF Ministry of Energy.

Wholesale market of electric energy and power. Federal Law of March 26, 2003 No. 35-Ф3 "On the Electric Power Industry" provides for the use of the mechanism for selling the capacity of generating facilities operating on the basis of renewable energy sources, under the DPM RES at the price and in the manner established by the Government of the Russian Federation. The renewable energy support mechanism consists of competitive selection of investment projects for the construction of generating facilities operating on the basis of renewable energy sources and the conclusion of selected renewable energy projects for renewable energy sources regarding selected projects. Decree No. 449 of May 28, 2013 approved the rules for determining the price of capacity for such generating facilities.

By order of the Government of the Russian Federation dated 01.01.2009 No. 1-r, for the implementation of the renewable energy support mechanism, indicators of the limit values of renewable energy generating facilities were established (Figure 1), target indicators of input volumes for each type of renewable energy generating facility for the period up to 2024 (Figure 2).

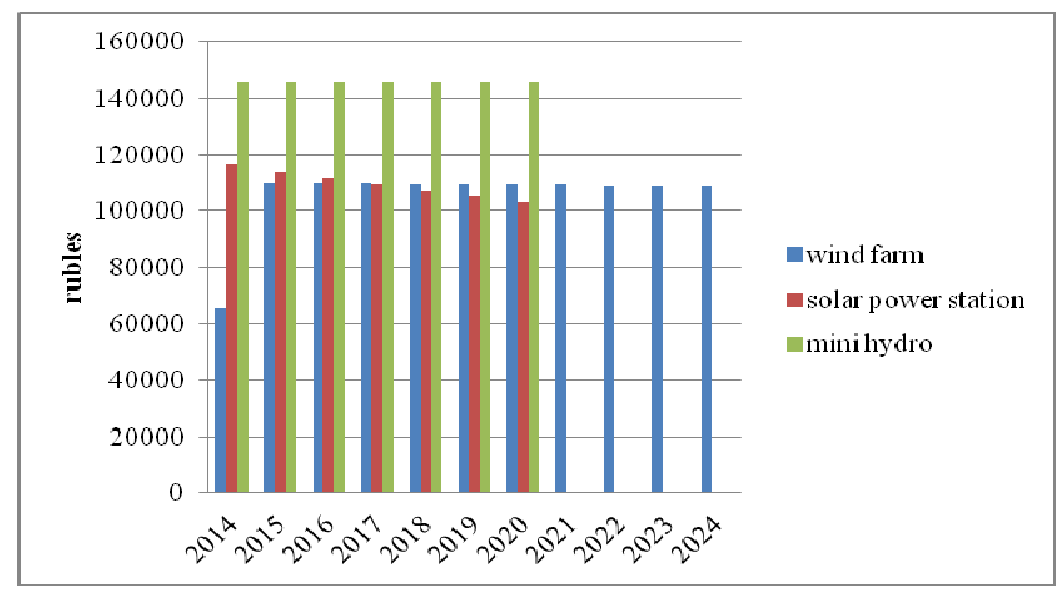

Fig. 1. Limit values of capital costs for charging $1 \mathrm{~kW}$ of installed capacity of a generating facility operating on the basis of renewable energy, rub.

The data presented show the maximum boundaries of the value of the contract participating in the auction for the construction of generating facilities operating on the basis of renewable energy sources. Thus, in 2019, the limiting value of the construction costs of $1 \mathrm{~kW}$ of installed capacity was: for the wind power plant 105,961 rubles, for the solar power station 105,262 rubles, mini-hydroelectric power plants 146,000 rubles. Analysis of the dynamics of indicators allows us to conclude that the cost of equipment for wind energy has risen 1.6 times in 5 years. In the field of solar energy, as noted, active 
research is being carried out, which allows providing the renewable energy market with new technologies. This leads to increased competition in the market in a wide range of solar panels. Therefore, as can be seen from the diagram, the cost of erecting $1 \mathrm{~kW}$ of installed capacity of a solar power plant is reduced annually.

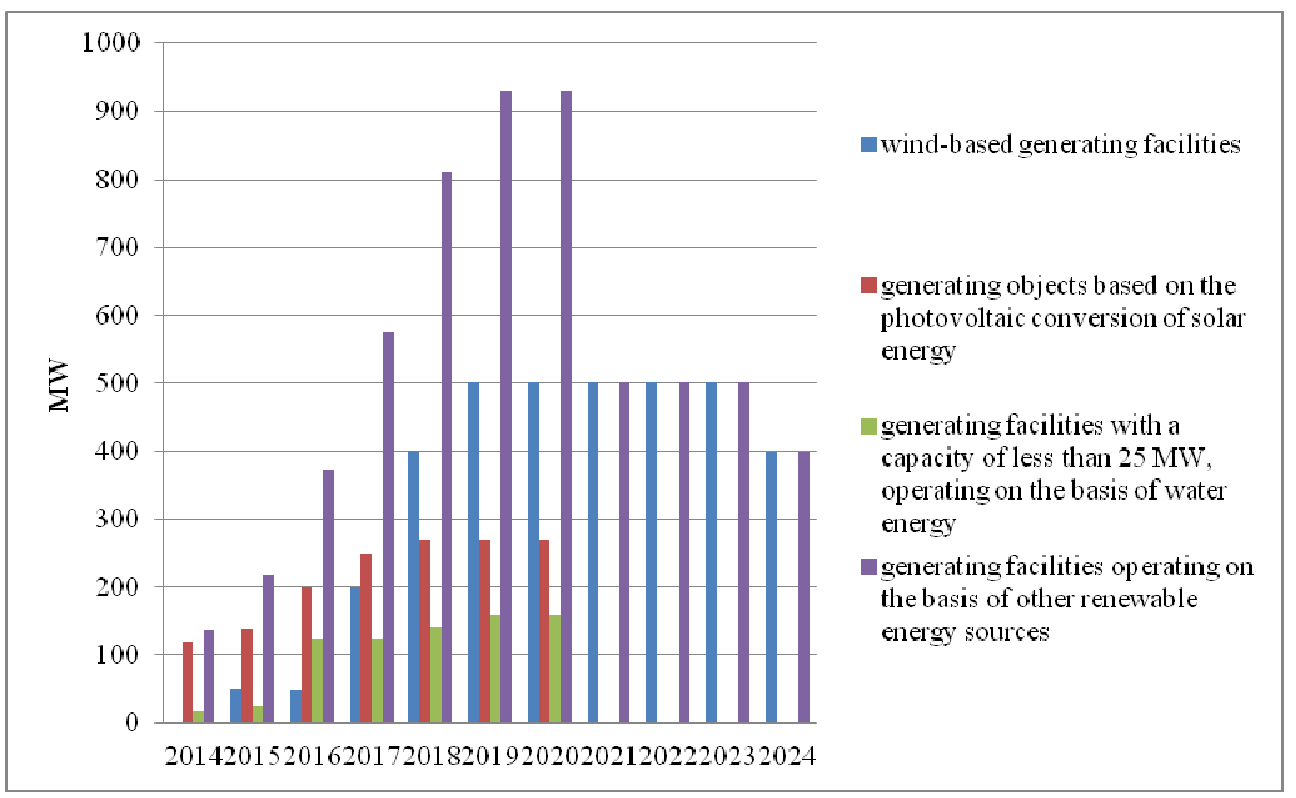

Fig. 2. Target indicators for commissioning the installed capacity of generating facilities operating on the basis of renewable energy sources, MW.

According to the planned input indicators for the capacity of generating facilities operating on the basis of renewable energy for 10 years of the program, $3600 \mathrm{MW}$ of energy generated by facilities operating on the basis of wind energy will be commissioned, $1520 \mathrm{MW}$ of energy generated by facilities operating on the basis of solar energy, $751 \mathrm{MW}$ of energy generated by facilities operating with installed capacity of less than $25 \mathrm{MW}$, operating on the basis of water energy, $5871 \mathrm{MW}$ of energy generated by facilities operating on the basis of other RES.

Target volumes of inputs and requirements for the degree of localization by years for each type of renewable energy generating facility are synchronized so that the main manufacturers of generating equipment can have an acceptable horizon for the return on investment. This issue is important to consider for the deployment of large production sites in the Russian Federation for the production of individual elements of generating equipment, as well as to achieve a sufficient level of development of competition in the market for such generating equipment, which can subsequently lead to a decrease in its final cost [11].

Support mechanisms in retail markets and in isolated energy areas. Decree of the Government of the Russian Federation dated 01/23/2015 No. 47 defines the procedure for implementing the mechanism for supporting renewable energy in retail markets in the price and non-price zones of the wholesale market, as well as in geographically isolated energy areas. This decision defines the procedure for the formation of long-term tariff regulation of renewable energy generating facilities in the retail markets, as well as the rules for their functioning.

Marginal levels of capital and operating costs are established by order of the Government of the Russian Federation dated 07.28.2015 No. 1472-p. 
Order of the Federal Antimonopoly Service of Russia dated September 30, 2015 No. 900/15 approved methodological guidelines for setting prices (tariffs) and (or) maximum (minimum and (or) maximum) price levels (tariffs) for electric energy (power) produced on the basis of the use of renewable energy sources by qualified generating facilities and acquired in order to compensate for losses in electric networks.

The procedure and conditions for conducting competitive selections for the inclusion of renewable energy generating facilities in the region's electric power industry development scheme, as well as requirements for relevant investment projects for the construction of renewable energy generating facilities and the criteria for their selection are established by regional authorities.

The adopted regulatory legal acts will allow the regional authorities of the constituent entities of the Russian Federation to independently make decisions on supporting renewable energy generating facilities, taking into account their economic and environmental feasibility and the adequacy of resources to ensure them in each specific case, subject to acceptable rates of growth in prices for electric and thermal energy.

In order to reduce the risks of making investment decisions on projects for the construction of renewable energy generating facilities, the Government of the Russian Federation dated 10.11.2015 No. 1210 amended the Rules for determining the price of capacity of generating facilities operating on the basis of renewable energy sources, approved by the government of the Russian Federation of 05.28.2013 No 449 .

\section{Discussion}

RES defines many issues of a political, economic and sociological nature. The Russian energy market and consumer are currently not motivated by the development of renewable energy sources. There is no strategy for the development of renewable energy sources that could systematize the tasks and programs in this area. To form a holistic view of the future course of renewable energy development, it is necessary to have a clear understanding of key beneficiaries.

Groups of persons that can be attributed to the beneficiaries should include: industry (entities interested in reducing the cost of energy resources); healthcare sector (entities interested in environmental aspects of renewable energy development, contributing to the preservation of public health); banks (entities interested in profitable investment with state guarantees). A separate issue in RES is the processing of solid waste. In this issue, it is necessary to take into account the tasks set in the national project "Ecology".

Let us turn to the experience of Germany. Energy prices in Germany are quite high and therefore the issue of switching to renewable energy has been relevant for many years. Here, the development of renewable energy sources has been supported for about 20 years and they make up $40 \%$ of the energy balance. Germany is gradually closing its nuclear and coal stations. To maintain a stable situation in the energy market, synthetic gas is used. Like other countries, there are also many problems that cause market volatility: there is a great need for the introduction of smart grids and energy storage systems. Auctions for offshore wind power can quickly reduce prices in the markets. Carbon emissions decreased by $40 \%$ compared to 1990, and GDP doubled. This means that it is possible to protect nature and at the same time ensure the country's economic growth. The development of renewable energy in Germany ensured a cash inflow of $\$ 8$ billion, due to the export of environmental technologies, regardless of political initiatives. If Germany did not have an environmental transition, then GDP would be lower by $1.3 \%$. This indicates the attractiveness of renewable energy.

The Russian Federation, as many experts note, is a major energy player in the market and therefore it should expand its prospects, given its potential. There are already several 
dozen technologies on the market: single-crystal, polycrystalline, thin films and others. All technologies have their competitive advantages. One of the advanced Russian developments is monosilicon type solar cells. In terms of quality, this technology is one of the most popular, with an average cell power above $23 \%$ efficiency.

\section{Conclusion}

In Russia, characteristic trends in the development of renewable energy sources are similar to those of other countries. The main share is still occupied by traditional generation. Until the year 50, a gradual shift in the place of traditional energy is planned due to the implementation of DPM-RES programs. Renewable energy needs significant additional support, and then it will develop independently, taking into account current conditions. At the moment, Russia has created its own production in terms of wind turbines, as well as production in terms of solar energy elements, the use of which is not limited by the country's borders; there is interest in Russian equipment both among European and Asian countries. In addition, it is planned the active development of small hydropower. A regulatory framework has been prepared for the development of retail micro-generation, where consumers will become active participants in the energy market, they will not only control electricity, but also sell it to the network. The main areas that need comprehensive interconnected development are: the retail energy market, the wholesale energy market, government regulation and support from the financial department for the provision of tax benefits for sellers who distribute energy into a common network. The introduction of changes in technical regulation for renewable energy facilities should give such a result as: a reduction in energy prices based on the development of renewable energy sources and the renewable energy facilities reaching parity with traditional generation.

\section{Reference}

1. BP, Energy Outlook: 2019 edition (2018)

2. T. Simankina, I. Kibireva, A.Mottaeva, M. Gusarova, Advances in Intelligent Systems and Computing. 983, 138-145, (2019) https://doi.org/10.1007/978-3-030-19868-8 13

3. K. Locmelis, D. Blumberga, U. Bariss, Energy Procedia, 147, 202-206 (2018) doi.org/10.1016/j.buildenv.2018.02.012

4. P. Bertoldi, F. Diluiso, L. Castellazzi, N. Labanca, T. Serrenho, Energy Consumption and Energy Efficiency Trends in the EU-28 2000-2015 (2018) doi:10.2760/6684

5. I. Potekhin, V. Mischenko, A. Mottaeva, A. Zheltenkov, E3S Web of Conferences, 33, 03020 (2018) doi: 10.1051/e3sconf/20183303020

6. G.Semenova, E3S Web of Conferences, 91 ,08047 (2019)

7. D. Zhikun, F. Ze, V.W.Y. Tam, B. Yu, L. Shenghan, I.M.C.S. Illankoon, M. Sungkon, Building and Environment, 133, 32-40 (2018) doi.org/10.1016/j.buildenv.2018.02.012

8. A. Bowen, K. Kuralbayeva, E.L.Tipoec, Energy Economics, 72, 263-275 (2018) https://doi.org/10.1016/j.eneco.2018.03.015

9. W.A. Pelser, J.C. Vosloo, M.J. Mathews, Journal of Cleaner Production, 198, 642-653 (2018) doi.org/10.1016/j.jclepro.2018.07.071

10. G. Ridauraa, S. Llorens-Cerveraa, C. Carrilloc, I. Buj-Corral, C. Riba-Romevaa, Resources, Conservation and Recycling, 131, 75-85 (2018) doi.org/10.1016/j.resconrec.2017.10.030 
11. M. Dieterle, Ph. Schäfer, T. Viere, Procedia CIRP, 69, 764-768 (2018) doi.org/10.1016/j.procir.2017.11.058

12. T. Meshcheryakova, MATEC Web of Conferences, 106, 06021 (2017) doi: 10.1051/matecconf/201710606021 